\title{
Data Envelopment Analysis and Social Enterprises: Analysing Performance, Strategic Orientation and Mission Drift
}

\begin{abstract}
This study endorses the use of data envelopment analysis, which uses benefit-of-the-doubt weighting to evaluate the social, economic and overall performance of social enterprises. This methodology is especially useful for creating composite indicators based on multiple outputs expressed in different measurement units, and allows for enterprise-specific weighting of the different objectives. Applying this methodology on a unique longitudinal dataset of Flemish sheltered workshops suggest that social enterprises may face different types of mission drift. Further, our results show that top-performing social enterprises are more economically and socially efficient than low performers. These top performers also have a stronger economic orientation, which sheds new light on the balance between social and economic orientations in social enterprises.
\end{abstract}




\section{Introduction}

Despite an impressive rise in the number of empirical studies in the social entrepreneurship literature, very few studies have addressed the performance of social enterprises (Ebrahim and Rangan 2014; Gulland 2011; Battilana and Lee 2014). Performance of social enterprises is complicated by their distinctive hybrid nature. Social enterprises operate at the crossroads of economic and social logics, and thus aim to achieve both social and economic performance simultaneously. This implies that such enterprises must embrace both social and economic organisational principles (De Clercq and Voronov 2011). These contrasting principles may result in social-business tension, which social enterprises must balance in order to achieve sustainability (Bruneel et al. 2016).

Stimulated by political and social trends that have made the environment of the social sector more competitive, social enterprises appear to be under pressure to become more business-like and adopt more profitable strategies (Wellens and Jegers 2014; Eikenberry and Kluver 2004). This has led to ethical trade-offs between the economic and social missions of social enterprises (André and Pache 2016), and this growing pressure on social enterprises may threaten their commitment to accomplishing their social missions (Ramus and Vaccaro 2014; Battilana et al. 2012). Thus, social enterprises are increasingly in danger of mission drift, which occurs when social enterprises abandon their social mission in favour of their economic mission (Battilana et al. 2012).

Although a substantial body of literature addresses how social enterprises may prevent mission drift (Smith et al. 2013; Ramus and Vaccaro 2014), we still lack an understanding of how to identify mission drift. Since assessment of dual performance plays an ethical role in social enterprises' strategic reflections on the potential risk of mission drift (Bull 2007; Ebrahim et al. 2014), performance measurement should be a central aspect of social entrepreneurship. More specifically, accurate measurement tools for social enterprises have a two-fold monitoring objective: (i) to report on social and economic performance; and (ii) to identify mission drift.

Operationalisation of performance measurement for social enterprises remains a daunting task because it must take account of a broad range of economic and social impacts (Chen et al. 2015; Ebrahim and Rangan 2014). As Certo and Miller (2008, p. 268) report, "performance for social enterprises is less standardized and more idiosyncratic to the organization", which makes performance measurement complex for a wide range of social enterprises (Gulland 2011). Therefore, this study builds on the reasoning that performance measurement should simultaneously reflect both social and economic objectives and the strategic orientation of social enterprises (e.g. Zahra et al. 2009; Certo and Miller 2008; Battilana and Lee 2014). Such methods should allow for unequal weighting of the social and economic objectives, as attending to these objectives is a matter of relative priority which 
varies across organizations (see Stevens et al., 2015b). Data envelopment analysis (DEA), which uses benefit-of-the-doubt (BoD) weighting, can be used for this purpose. It is especially useful for creating composite indicators based on multiple outputs expressed in different measurement units, and it allows for enterprise-specific weighting of the different objectives.

The study also makes several contributions to the current literature on social entrepreneurship and strategic management. First, it enhances our understanding of the social, economic and overall performance of social enterprises. DEA highlights empirically the social enterprise's position in relation to social and economic outcomes. In drawing on a longitudinal dataset, this article takes an important step forward with respect to empirical weaknesses of the current literature, in terms of small sample sizes and short timescales (Battilana and Lee 2014).

Second, the dynamic features of DEA also allow us to monitor the social enterprise's mission orientation over time. Specifically, following the BoD logic, we can track shifts in the relative weightings attributed to social and economic missions (e.g. Cherchye et al. 2007a, 2007b; Belu 2009; Kuosmanen and Kortelainen 2005). These weightings are strong indications of the amount of attention devoted to the respective missions (Cherchye et al. 2007b), informing us about their relative priority and thus the organization's strategic orientation (Stevens et al. 2015b). As a result, changes in weights can be used as a proxy for analysing potential mission drift, which is considered mainly in terms of a decrease in the strategic priority of social goals in favour of economic goals (Doherty et al. 2014). Hence, DEA provides an opportunity to specify empirically whether social enterprises are operating ethically at the crossroads of social and economic performance, and which direction they are tending to follow over time.

Third, we make a significant methodological contribution to the strategic management literature by using DEA to study the performance and mission drift of social enterprises. DEA has been used extensively in the literature on organisational efficiency, but very few strategic management studies have drawn on this method. As recently observed by Chen et al. (2015), this is surprising, as DEA provides an opportunity to analyse the competitive advantage of organisations.

Drawing on a unique longitudinal dataset containing the full population of Flemish sheltered workshops, which are work-integration social enterprises, this paper shows how DEA can be applied to measure performance and track potential mission drift. Our findings shed new light on mission drift in social enterprises. In contrast with the argument of previous literature that social enterprises face mission drift in sacrificing their social mission in favour of their economic mission, our findings show that social enterprises may face different types of drift. The bottom performers face mission lock-in, meaning that they systematically over-emphasise social objectives and lose sight of economic aspects. 
Consequently, they are unable to improve both social and economic performance over time. Our findings further show that social enterprises may face "reverse" mission drift, where they pay greater attention to social performance at the expense of economic performance. Our study also provides a more nuanced perspective on the ethical challenges of social enterprises by revealing new insights on "good" and "bad" behaviours of social enterprises. We show that top-performing social enterprises have greater economic and social efficiency than poor performers. Interestingly, these top performers also have a stronger economic orientation, shedding new light on the balance between social and economic orientation in social enterprises. Specifically, social enterprises with a greater emphasis on commercial activities to realise economic goals, as reflected in their stronger economic orientation, also achieve better social performance. Thus, social enterprises that place a relatively high emphasis on the economic tend to have better success over time, thereby achieving long-term sustainability.

\section{Social Entrepreneurship and Dual Objectives}

In line with a substantial body of literature encouraging a broad definition of social enterprises, we define social entrepreneurship as entrepreneurship with an embedded social purpose, which is sustainable through trading (Stevens et al. 2015a). Derived from this broad definition, social enterprises thus position themselves between two ends of a continuum, or the so-called social enterprise spectrum, between economic and social missions (Dees 1998). Consequently, they differ in the extent to which they adhere to their social and economic missions, resulting in a continuum of possibilities with varying degrees of attention to social and economic goals (Stevens et al. 2015a). While economic goals relate to an organisation's financial sustainability, a broad definition of social goals captures their impact on the local community, the environment, society in general, and people working in the organisation.

As a result of their dual objectives, social enterprises must manage the idiosyncratic, paradoxical tension between their desire to create social value and their maintenance of economic efficiency for organisational sustainability (see e.g. Battilana et al. 2015; Dacin et al. 2010). Since these dual objectives are not necessarily aligned, and may even conflict, the literature suggests that ethical challenges and instability may arise (Battilana et al. 2012), resulting in mission drift (Ebrahim et al. 2014). In the context of social entrepreneurship, this happens especially if a firm over-emphasises its economic objectives and neglects its social ones (Young et al. 2012), placing it in danger of breaking its social traditions and moving abruptly from the social to the economic end of the social enterprise spectrum. While previous studies have enriched our understanding of how social enterprises may deal with these challenges (Battilana et al. 2015), we lack a systematic analysis of the sustainability of their commitment to social and economic objectives over time. A complication of performing such studies 
is the lack of a methodology allowing for the measurement of both the social and economic performance of social enterprises.

\section{Performance Measurement of Hybrid Social Enterprises}

Current Tools for Performance Measurement of Hybrids

There are two main streams of research on performance measurement for social enterprises. First, in line with the traditional belief that social value is created by non-profits and economic value is created by for-profits (Maas and Liket, 2011), it is unsurprising that substantial research has focused purely on either social or economic value. Within this one-dimensional performance approach, some have adopted measurement practices from the private sector, such as expenditure and operating expense ratios, to measure solely economic performance (Kaplan 2001). Others have employed methods such as SROI analysis, social scorecards, social auditing, corporate social responsibility scores, eco-efficiency measurements, and even life satisfaction ratings as a means to measure purely social performance (see Maas and Liket 2011; Kaplan 2001; Kuosmanen and Kortelainen 2005; Flockhart 2005; Kroeger and Weber 2014).

These different approaches have proved useful for organisations that have a purely social or economic mission, such as private companies and charities. However, their usefulness for social enterprises has tended to be disappointing, as they neglect the crucial assumption that social entrepreneurs pursue social and economic missions simultaneously (Dacin et al. 2010). This parallels Zahra et al.'s (2009) notion that the performance measurement of social enterprises should reflect their "total wealth" creation (i.e. social and economic wealth); for example, Battilana et al. $(2012$, p. 55) report that "a critical step will be the development of measurement and reporting systems that recognize both social and financial value".

The second stream of research takes these calls into account by using multidimensional frameworks that blend different types of value creation. Methods such as "balanced scorecards" (e.g. Bull 2007; Kaplan 2001), blended value accounting (e.g. Nicholls 2009), blended return on investment (e.g. Flockhart 2005) and the competitive analysis matrix for social entrepreneurs (e.g. Boschee 1995) are profound examples. However, these approaches do not provide the numerical outputs necessary to make consistent comparative analyses across organisations, nor adequate theory testing through statistical analysis. More specifically, current approaches are unsystematic (Hart and Haughton 2007; Gulland 2011), are frequently subjective in the importance attached to the dual goals (Flockhart 2005), are contextually bounded (Millar and Hall 2012), often fail to yield a final standardised figure for performance (Rotheroe and Richards 2007), and have limited comparability across enterprises (Kroeger and Weber 2014). 
In short, while one-dimensional measures do not represent the total performance of social enterprises, multidimensional approaches face incommensurability problems. Accordingly, these measurement methods are useful management tools for individual organisations (Kaplan 2001), but not for crosssectional or longitudinal empirical analyses. Consequently, most empirical social entrepreneurship studies focus on single or multiple case studies (Dacin et al. 2011; Gulland 2011). Although these studies provide valuable insights, lack of empirical work on large-scale databases limits our understanding of social enterprises, and particularly the tension between social and economic objectives (Certo and Miller 2008).

\section{Challenges in Measuring the Performance of Social Enterprises}

The lack of a standard performance methodology in social entrepreneurship raises many questions about measuring the dual performance of social enterprises. How can we measure social and economic performance? How can we aggregate these sub-indicators? How can we deal with social enterprises' heterogeneous mission orientation? How can we compare the performance of different social enterprises? So far, scholars have shed light on two key practical and methodological issues that need to be addressed to answer these questions: first, the aggregation of different objectives in a meaningful way while allowing for the idiosyncrasy of each firm; and second, handling different objectives with different units of measurement (i.e. normalisation).

The first concern relates to an assumption that social enterprises face a distinct challenge in trying to optimise performance across multiple dimensions as they pursue multiple objectives simultaneously; yet these firms are free to choose which route to follow, and thus differ in the extent to which they adhere to their social and economic missions (Stevens et al, 2015a). Consequently, goal duality should be meaningfully aggregated and aligned in an appropriate performance measure that reflects the route between the dual objectives being pursued, and thus captures blended value creation (Battilana et al. 2012). However, measuring social and economic goals together causes an aggregation problem, as there is no obvious way of weighting strategic goals (e.g. Cherchye et al. 2007a). Part of the problem relates to the fact that it is often more convenient to fix the relative importance of goals for the whole sample. Nevertheless, as discussed by Cherchye et al. (2007b), fixing the weightings of goals, for example by attributing equal weightings, is often thoroughly misleading.

The second concern relates to the normalisation problem of aggregating sub-indicators that have no common, meaningful measurement unit (see Cherchye et al. 2007a). In the context of social entrepreneurship, social and economic indicators are expressed in different measurement units, both non-financial and financial. For instance, WISE offering jobs to disadvantaged people may express their 
social performance in terms of the number of people hired by the organisation, while expressing their economic performance through classical monetised indicators (Crucke and Decramer 2016).

Taken together, measuring the performance of social enterprises requires consideration of their dualobjective and idiosyncratic orientation, necessitating the use of composite indicators. For social enterprises, these composite indicators need to incorporate both social and economic objectives simultaneously and allow for enterprise-specific weighting. One such approach is the nonparametric programming technique known as data envelopment analysis (DEA), which uses so-called benefit-ofthe-doubt $(B \circ D)$ weighting.

DEA has been shown to be instrumental in overcoming the problems of aggregation and normalisation (see Cherchye et al. 2007a). Although DEA was first introduced in the literature on organisational efficiency, it has received increasing attention as a management tool in economic and strategic management literature. For instance, DEA has already proved able to address the challenges of environmental performance measurement, in terms of eco-efficiency (e.g. Chen and Delmas 2011; Kuosmanen and Kortelainen 2005) and corporate social responsibility (e.g. Belu 2009; Lu et al. 2013; Sun and Stuebs 2013). Several recent studies have used DEA to measure social and economic efficiency in microfinance institutions (e.g Basharat et al. 2015; Martínez-Campillo et al. 2016; Gutiérrez-Nieto et al. 2009; Bharty and Chitnis 2015) and fair trade shops (Bellucci et al. 2012). Nevertheless, these studies have bypassed the advantage of BoD weightings of creating a composite indicator of dual objectives in order to take into account and map the strategic orientation of these organisations.

\section{Weighing up the Benefit of the Doubt using Data Envelopment Analysis}

DEA is a performance benchmarking technique which assesses how efficiently firms transform inputs into outputs (Chen et al. 2015). The DEA literature addresses ways of measuring the efficiency of a sample of similar entities, given their input and output quantities, in settings in which one has no knowledge of the "functional form" of a production function (Cherchye et al. 2007b). In a one inputone output case, an intuitive way of expressing efficiency is:

$$
\frac{Y_{0}}{X_{0}}
$$

with input $X_{0} \in \mathbb{R}_{+}$and output $Y_{0} \in \mathbb{R}_{+}$. The higher this efficiency score, the better the firm is performing. Using these scores, it is even possible to rank all available firms in a dataset to identify the top and bottom performers (Cherchye et al. 2007b). In a realistic multiple input-multiple output case with inputs $X_{0} \in \mathbb{R}_{+}^{m}$ and outputs $Y_{0} \in \mathbb{R}_{+}^{S}$, it is useful to retain a single composite indicator representing performance. Therefore It is necessary to aggregate the inputs and outputs in some way: 


$$
\Theta=\frac{u_{1} Y_{01}+\cdots+u_{s} Y_{0 s}}{v_{1} X_{01}+\cdots+v_{m} X_{0 m}}=\frac{\sum_{r=1}^{s} u_{0 r} Y_{0 r}}{\sum_{i=1}^{m} v_{0 i} X_{0 i}}=\frac{u_{0} Y_{0}^{T}}{v_{0} X_{0}^{T}}
$$

The weightings $v_{0} \in \mathbb{R}_{+}^{m}, u_{0} \in \mathbb{R}_{+}^{s}$ allow the importance of certain inputs (outputs) to be emphasised over other inputs (outputs). Except when all inputs and outputs have a monetary value (e.g. in US dollars), the choice of appropriate weightings is debatable and depends on the viewpoints of different stakeholders or different firms. To avoid such debate, the weightings for each firm can be derived such that every firm has the best possible performance (Cherchye 2001). This prevents organisations from claiming that their performance is being evaluated with an unfair weighting scheme, as any other weighting scheme would only worsen their position with respect to the other organisations in the sample.

Interestingly, DEA has been labelled as a "benefit-of-the-doubt" approach. This label derives from one of DEA's main conceptual starting points: that an appropriate weighting scheme for an organisation can be retrieved from the dataset itself (Cherchye et al. 2007a). Thus, DEA endogenously identifies the most favourable weighting scheme for an organisation, given the whole population. Specifically, DEA solves an optimisation problem, whereby all possible efficiencies are calculated under all possible weighting schemes for each observation of the whole population. Based on this optimisation problem, the most favourable weighting scheme is obtained for each organisation. Importantly, Cherchye (2001) shows that these weights can be used as proxies for the strategic priority of objectives. This approach has been well-established in the context of policy performance assessment to aggregate indicators that reflect country-specific policy priorities (e.g. Zaim et al. 2001; Cherchye and Kuosmanen 2006). Moreover, DEA has proved to be particularly appropriate when there is no clear profit maximisation objective (Belu, 2009) or when prior weighting of the objective is ambiguous (Cherchye 2001; Cherchye et al. 2007a; Kuosmanen and Kortelainen 2005; Chen and Delmas 2011). Consequently, these weightings can justifiably be used as proxies for the priority of social and economic goals, and thus for the position of social enterprises on the continuum.

\section{DEA Formulation}

DEA was pioneered in the seminal works of Charnes et al. (1978) and Banker et al. (1984). Charnes et al. (1978) proposed the following nonlinear programming problem to evaluate firm 0 against all other $n$ firms. Note that minimising $\frac{v X_{0}^{T}}{u Y_{0}^{T}}$ is equivalent to maximising $\frac{u Y_{0}^{T}}{v X_{0}^{T}}$, as discussed earlier:

$$
\frac{1}{\Theta} \equiv \min _{v, u} \frac{v X_{0}^{T}}{u Y_{0}^{T}}
$$




$$
\begin{gathered}
\text { s.t.: } \frac{v X_{j}^{T}}{u Y_{j}^{T}} \geq 1, \quad j=1, \ldots, n \\
u, v \geq 0
\end{gathered}
$$

This delivers an efficiency score $\theta$ situated between 0 and 1 . Note that weightings $u$ and $v$ are calculated following the BoD, and thus the most favourable weightings are applied for each organisation. Apart from non-negativity, the above DEA program has complete freedom to choose appropriate weightings $u$ and $v$. For BoD composite indicators in particular, there remains the inherent difficulty that weightings may take unreasonable values (Kuosmanen and Kortelainen 2005). For example, in the context of social enterprises, it would be unrealistic for these firms to have zeroweightings for any of their outputs. In such cases, the firms would have a pure social or economic focus, conflicting with the assumption that social enterprises are hybrid organisations. To improve the realism of an application, expert knowledge of the strategic weighting schemes of the sample can be included. Such additional information regarding trade-offs between different inputs and outputs can be incorporated by adding suitable weighting restrictions to the model (for a discussion, see Cherchye et al. 2007b). In particular, we can add $K$ restrictions of the form:

$$
u Q_{k}^{T}-v P_{k}^{T} \leq 0, k=1, \ldots, K, \quad \text { with } P_{k} \in \mathbb{R}^{m} \text { and } Q_{k} \in \mathbb{R}^{s}
$$

For the setting of a social enterprise, one can simulate the two-ended continuum by imposing relative weighting restrictions for the outputs in the form $\frac{1-p}{p} \leq \frac{u_{1}}{u_{2}} \leq \frac{p}{1-p}$, with $0 \leq p \leq 1$, and $p$ representing the maximum attention allocated to financial relative to social performance. This weighting restriction results in a two-ended continuum with borders $p$ and $1-p$. For example, by setting $p=0.8$, the twoended continuum allows firms to have varying levels of attention between 0.2 and 0.8 distributed between social (u1/(u1+u2)) and economic (u2/(u1+u2)) goals.

\section{Advantages of Using Data Envelopment Analysis for Performance Measurement of Social Enterprises}

Using the BoD composite indicators of DEA to examine the performance of social enterprises offers several distinct advantages over the currently available performance tools discussed above. First, DEA is a nonparametric methodology, meaning that it does not resort to parametric or functional specifications, but rather "lets the data speak for themselves" (Cherchye et al. 2013, p. 1148). Thus, DEA may be particularly useful when data and/or information is limited for any reason, as it simply compares the reported inputs and outputs of the firm being evaluated to those of other firms operating in a similar environment (Cherchye et al. 2014). This is a particularly important advantage in the case of social entrepreneurship, where available data is limited and information on the idiosyncratic relative importance of objectives is scarce. 
Second, DEA is characterised by BoD weighting. If a firm performs well on a particular dimension, a high relative weighting is allocated to that dimension. Because good performance on a particular dimension has been recognised as a good indicator of its strategic priority, the calculated weightings may be used as proxies for the organisation's mission orientation (Cherchye et al. 2007b). In effect, BoD weighting assumes that a firm's performance reflects its strategic priority, and thus its position on the two-ended continuum. Moreover, shifts in weightings may reflect changes in the priorities of organisational objectives over time and thus its mission orientation (Gonin et al. 2012). As Cherchye (2001) illustrates that DEA weightings provide an accurate indication of true priorities between objectives, this appears to be a reasonable assumption. For example, his paper explains how DEA allows governmental policy priorities to be estimated.

Third, with respect to this BoD advantage, DEA does not require prior (subjective) judgements about weightings. Nevertheless, prior information can still be incorporated into the framework by adding additional weighting restrictions, which should be justified on appropriate normative grounds (for a discussion, see Cherchye et al. 2007b). In the context of social entrepreneurship, this may be useful whenever prior information is available on the possible boundaries of the two-ended continuum.

Lastly, DEA is invariant to measurement units for both input and outputs. This property is extremely useful in the context of social enterprises because it facilitates comparisons of efficiency across different social enterprises without concern for measurement units of social and economic performance.

\section{Analysing Performance and Mission Drift in Social Enterprises using DEA: The Case of Work-Integration Social Enterprises}

\section{Motivation and Sample Selection}

We consider the case of WISE in Flanders, Belgium. These organisations aim to re-integrate long-term unemployed people into the regular labour market by hiring them to produce products and services that are sold in a competitive marketplace. In particular, we examine the complete population of Flemish sheltered workshops that employ people with disabilities as this constitutes a homogenous groups of social enterprises (Crucke and Knockaert 2016). The social mission of these workshops is to help integrate people with disabilities into society by offering them meaningful job opportunities. These firms receive subsidies to compensate for productivity loss arising from employing people with disabilities. In addition to these subsidies, they also rely on financial revenues from commercial activities to achieve long-term sustainability.

DEA is a technique for assessing the relative efficiency of a 'comparable' (i.e. 'homogeneous') group: this assumption implies that the organizations under study belong to one production frontier (Golany 
\& Roll, 1989). Hence, focusing on this homogeneous population of social enterprises provides important methodological advantages for the use of DEA. Sheltered workshops share several key characteristics: (1) a social mission of employing people with disabilities, (2) a portfolio of low-skilled activities tailored to people with disabilities, (3) a non-profit legal form, (4) a similar regulatory environment, and (5) the same governmental legal accreditation, namely "Beschutte Werkplaats". All sheltered workshops are also categorised under the same (NACE-BEL) activity code, "88995 Beschutte and Sociale werkplaatsen" - which categorises firms based on their economic and production activities. These similarities justify our assumption that these organisations share the same production frontier. Consequently, we assume that differences in efficiency are caused by managerial decisions, such as strategic orientation (translated into weightings in DEA calculations). This is in line with Crucke and Knockaert (2016), who used the same population in their study for homogeneity reasons.

This study makes use of a unique dataset collected by the Flemish Department for Work and Social Economy (WSE). It comprises the full population of 55 Flemish sheltered workshops and is longitudinal, with 542 observations from 2004 to $2013 .{ }^{1}$ As such, this paper responds to scholarly calls to go beyond small case studies and to construct large-scale longitudinal databases (Gulland 2011; Battilana and Lee 2014; Dacin et al. 2011). The Flemish WSE Department collected detailed information annually on the composition of the workforce across different groups of employees (regular and target employees). In addition, we collected all available financial data from annual accounts, and interviewed experts in government, sector organisations and sheltered workshops to develop a deeper understanding of the sector

\section{Selection and Measurement of Input and Output Variables}

Since input/output selection is a key issue in the calculation of DEA efficiency, it is important to develop a relevant model (Gutiérrez-Nieto et al. 2007; Martínez-Campillo et al. 2016). To identify a relevant model, we examined the efficiency literature in the fields of strategic management (e.g. Banker and Natarajan 2008; Chen et al. 2015) and microfinance institutions (e.g. Basharat et al. 2015; GutiérrezNieto et al. 2009; Martínez-Campillo et al. 2016). These typically adopt a so-called ACE input model based on assets (A), costs (C) and employees (E). Assets represent physical capital inputs and employees reflect human capital inputs, while cost inputs reflect general operating costs. We opted for two outputs representing social (S) and economic (E) respectively. Thus, the ACE-SE model is a specification that includes three inputs (assets, costs and employees) and two outputs (social and economic). 


\section{Description of Variables}

Under this ACE-SE model approach, variables are required to represent the inputs used by organisations to achieve social and economic efficiency (Martínez-Campillo et al. 2016). To translate this model into the setting of Flemish sheltered workshops and to understand better how these inputs are necessary to achieve social and economic goals, we conducted interviews with field experts. In consultation with these experts and in line with the literature, we used three inputs: fixed tangible assets, contingent and operating costs. These inputs reflected the capital, costs and labour used by sheltered workshops to maintain their social and economic outputs measured by the number of employees with disabilities, and economic outputs measured by turnover.

\section{Input Variables}

Fixed tangible assets represent an organisation's physical operational assets, or property, plant and equipment. These items are considered as long-term investments essential to the day-to-day running of the sheltered workshops, and are therefore crucial to both economic and social missions. It is through investments in fixed tangible assets that these organisations ensure and create employment for their target employees. Using fixed tangible assets as a proxy for assets or capital input is consistent with other studies that have used fixed tangible assets as an input into their DEA calculations (e.g. Halkos and Tzeremes 2010; Rodríguez-Pérez et al. 2011).

Contingent is a sector-specific, labour-related variable. It represents the maximum annual number of subsidised employment places for target employees accredited by the government in each sheltered workshop. Although the social enterprises are free to determine their own contingent, and thus to employ fewer or more target employees than their contingent, the subsidies received are limited to their allocated contingent in terms of their actual employment of target employees. Hence, contingent is an important determinant of the employment opportunities offered by the sheltered workshop, and is thus an input into achieving its social and economic objectives. Managers of sheltered workshops whom we interviewed generally agreed on the importance of contingent as a determinant of their social and economic goals.

Operating costs represents expenses relating to operations, including all personnel expenses, depreciation, cost of goods sold, rent and utilities. These expenses are associated with the day-to-day running of the sheltered workshops, and are thus inputs into realising their economic activities and employing people with disabilities. Many other studies have used operating costs as an input variable in DEA models to assess efficiency (e.g. Basharat et al. 2015; Gutiérrez-Nieto et al. 2007, 2009). 


\section{Output Variables}

Revenue is a classical measure for assessing economic output in DEA studies (see Chen et al. 2015; Basharat et al. 2015; Gutiérrez-Nieto et al. 2009). Revenue is income received by sheltered workshops from their normal economic activities, usually from the sale of goods and services to customers.

Number of disadvantaged employees is used to operationalise the social output of sheltered workshops. This is in line with Ebrahim and Rangan (2010) and Crucke and Decramer (2016), who argue that WISE offering jobs to disadvantaged people may express their social performance in terms of the number of people they hire. This measure is justified since the central social mission of these organisations is the social and professional integration of disadvantaged workers through employment. Whenever feasible, these workers eventually pass through into the regular market, but only a very small proportion are able to do so.

Descriptive statistics of the inputs and outputs are provided in Table $1 .^{2}$ This table indicates that the sheltered workshops have a contingent of 255 target employees, and employ an average of 260 people with disabilities; thus, they employ more people with disabilities than their contingent, on average.

\section{Insert Table 1 about here}

\section{Results}

Efficiency Scores: Overall, Social, and Economic Performance

This section applies the BoD weighting method to performance analysis of Flemish sheltered workshops, using the relative weighting restriction $\frac{1-p}{p} \leq \frac{u_{1}}{u_{2}} \leq \frac{p}{1-p}$ with $p=0.8$. This weighting scheme derives from a survey conducted in 2016 ( $n=34$, representing a response rate of 62 per cent of the full population) which asked the sheltered workshops to allocate 100 points between their social and economic missions. This procedure generates a weighting scheme that complies with a limited expert consensus, but still deals with the remaining uncertainty using the BoD logic. According to the survey scores, the points allocated to each mission varied between 20 and 80 (with a mean of 51 points and a standard deviation of 12 ).

To gain additional insights into the dual objectives, social and economic efficiency scores were calculated in addition to overall efficiency. This was done by forcing a zero weighting for social and economic outputs in turn. Hence, we obtained efficiency scores from three different weighting schemes, resulting in scores for overall efficiency (ACE-SE model), economic efficiency (ACE-E model) and social efficiency (ACE-S model). Table 2 shows the descriptive statistics for these three models. As previously mentioned, DEA provides a benchmark against which organisations can be compared, 
where an efficiency of 100 per cent represents what is technically feasible. These relative efficiencies are thus closely related to the concept of competitive advantage, which occurs when an organisation is able to outperform its competitors (Chen et al. 2015). Regarding the total period, sheltered workshops performed at an acceptable overall efficiency level of 91.52 per cent. This indicates that they generated only 8.48 per cent less than the maximum, technically feasible level. The Flemish sheltered workshops achieved significantly lower economic than social efficiency: 67.90 per cent versus 85.78 per cent, on average. Given their inputs, it is thus technically feasible for sheltered workshops to improve their social efficiency by 14.22 per cent and economic efficiency by 32.10 per cent, on average. In summary, sheltered workshops have more opportunity to improve overall efficiency by enhancing economic efficiency.

Insert Table 2 about here

To examine the potential evolution of performance, we mapped average overall, social and economic efficiencies over time (see Figure 1a). Although average overall efficiency remained consistent, social and economic efficiency were more dynamic over time. The dynamics of these efficiency scores can be linked to two sub-periods, namely the financial crisis from 2007 until 2011, and a period characterised by uncertainty in policy relating to subsidies from 2011 to 2013. During the financial crisis, these organisations' economic efficiency dropped by five per cent, while their social efficiency improved slightly by three per cent, on average. Besides a general revival of the Belgian economy, the period between 2011 and 2013 was also characterised by considerable uncertainty in the institutional context of the Flemish social economy. The sector was preparing itself for a new decree (Maatwerk Decree) which would change the institutional context, and especially subsidy schemes for sheltered workshops. The aim of this decree was to professionalise the social sector and to make the social economy more self-financing. Therefore, sheltered workshops needed to comply with new requirements and to become more self-financing. During this period of uncertainty in regulations and subsidies, sheltered workshops faced growing pressure from the government to become more business-like. In response to the more favorable economy together with higher a regulative uncertainty, they increased their economic efficiency by six per cent, but this pressure seemed to erode their social efficiency, which dropped by five per cent.

Insert Figure 1 about here

Comparing the Top-, Mid- and Bottom-Quartile Performers

To understand these observations in more detail, we divided the population into three groups, namely top-, mid- and bottom-quartile performers (see Figures $1 \mathrm{~b}, 1 \mathrm{c}$ and $1 \mathrm{~d}$ ). ${ }^{3}$ These groups were conditioned 
on the average overall performance during the study period. The top-quartile performers consisted of 13 organisations that achieved the highest overall efficiency on average over all years; the bottomquartile performers consisted of 13 organisations that achieved the lowest overall efficiency on average; and the mid quartile comprised 29 organisations positioned in the mid quartiles in terms of overall efficiency on average. Focusing on these quartiles enabled us to track how these groups behaved over time to maintain their relative performance during the sub-periods.

Insert Table 3 about here

Table 3 illustrates that the top quartile achieved higher social and economic efficiencies than the mid and bottom quartiles. ${ }^{4}$ This indicates that the top performers had a competitive advantage over the other sheltered workshops on all dimensions. In comparison with the top performers, the bottom performers were less successful in adhering to both types of goal simultaneously, as their overall efficiency was 13.77 per cent lower than the top quartile, on average. More strikingly, the bottom quartile arrived at an economic efficiency of only 55.98 per cent, on average. It was thus technically feasible for the bottom quartile to improve its economic efficiency by 44.02 per cent. Nevertheless, at the end of the period of observation, their economic efficiency had increased only slightly over time, to 60 per cent, compared with the top performers' economic efficiency of 82.6 per cent (see Figures $1 \mathrm{~b}$ and $1 \mathrm{~d})$.

\section{Weighting Allocation to Social and Economic Efficiency: Analysing Strategic Orientation}

The weightings allocated to economic versus social objectives are proxies for the attention allocated to each objective, and thus for strategic priority (Cherchye 2001). Differences in weighting allocations may indicate social enterprises' differing strategic orientations to social and economic missions (Stevens et al. 2015b). In Figure 2, we compare the magnitude of the relative weightings of economic

$\left(\frac{u_{2}}{u_{1}+u_{2}}\right)$ versus social objectives $\left(\frac{u_{1}}{u_{1}+u_{2}}\right)$ for the top-, mid- and bottom-quartile performers in overall efficiency.

Insert Figure 2 about here

Figure 2 illustrates that the top performers systematically allocated higher weightings to economic performance than the low and mid quartiles. Hence, the relatively large overall competitive advantage of top performers (13.77 per cent over the bottom and 6.49 per cent over the mid quartiles, on average) can be attributed to their greater systematic attention to economic efficiency. This also 
translates into the fact that top performers had a larger competitive advantage from an economic point of view (22.99 per cent over the bottom quartile and 10.41 per cent over the mid quartiles, on average), than from a social point of view (10.63 per cent over bottom performers and 5.68 per cent over the mid quartiles).

Furthermore, there was a downward trend in the weightings allocated to economic objectives by all three groups during the financial crisis. However, in contrast to the bottom and mid quartiles, those in the top quartile were able to maintain their levels of economic efficiency, and thus did not sacrifice economic efficiency to improve social efficiency (see Figures $1 b, 1 c$ and $1 d$ ). For instance, the economic efficiency of the bottom and mid quartiles dropped by more than five per cent during the crisis, while their social efficiency remained fairly constant.

After the crisis, the top-, mid- and bottom-quartile sheltered workshops increased their economic orientation during the period of institutional uncertainty and economic revival. Uncertainty about subsidies for the social economy forced organisations to increase their economic orientation to ensure sustainability. Consequently, the top-, mid- and bottom-quartile organisations improved their economic efficiency at the expense of social efficiency (see Figures $1 b, 1 c$ and $1 d$ ). Notably, figure 2 shows that after 2011 the bottom performers were increasing their economic orientation more than the top and mid quartiles. Nevertheless, as they had more room for improvement compared to the other organizations (i.e. lower economic efficiency) (Belu, 2009; Cherchye et al., 2013), they were more likely to improve their economic efficiency with a lower deterioration of their social efficiency (see figure 1). Future research efforts could investigate in more detail the reasons behind and the difference between shifts in weights.

We performed several robustness tests to ensure the accuracy of our findings and to check whether top performers might appear to be efficient even if they performed well only on a single output. First, we ran two additional analyses using alternative weighting schemes for $\frac{1-p}{p} \leq \frac{u_{1}}{u_{2}} \leq \frac{p}{1-p}$, namely with no weighting restrictions $(p=0)$ and equal weightings $(p=0.5)$. Recall that we used $p=0.8$ in the reported analysis to increase realism and to show how weighting restrictions can be technically imposed. The correlations between the efficiency scores for $p=0.8$ and $p=0$ or $p=0.5$ were high $(>0.82)$ and significant at a p-value level of $<1 \%$ (see Appendix, Table A). Hence, analyses using these alternative weighting schemes generated similar results to those reported above. This indicates that all-round performing firms were not at a disadvantage compared with firms with purely social or economic efficiency. Moreover, the top performers were good all-round performing firms that achieved high social and economic efficiency. 


\section{Discussion and Contributions to the Literature}

The main purpose of this study is to propose DEA as a new performance measurement approach for social enterprises that addresses the methodological issues of existing performance tools. Through our discussion of the DEA methodology and its application in the context of WISE companies, we make several contributions to the social entrepreneurship literature.

\section{DEA and Social Enterprises: Performance Measurement and Strategic Orientation}

The first contribution is associated with providing a novel methodology for measuring the performance of social enterprises. There has been lively debate in the literature about how to measure the performance of organisations pursuing multiple goals (Ebrahim and Rangan 2014; Gulland 2011). Unfortunately, current research on this topic fails to propose a methodology that can handle the complexities of performance measurement of social enterprises. Besides the general advantages of DEA, using this performance technique also offers several unique benefits for the performance measurement of social enterprises.

First, DEA allows for the aggregation of multiple outputs expressed in different measurement units. Irrespective of how social performance is measured, DEA generates efficiency scores for overall, social and economic efficiency which are easy to compare and interpret. As a result, the BoD technique in DEA is more suited than current tools to reflecting the achievement of social and economic objectives in composite indicators.

Second, the DEA technique is characterised by the BoD property. Optimal weighting schemes between different types of performance are derived from data for each firm individually; thus, inefficiencies cannot be due to unfavourable weightings. Furthermore, these weightings act as proxies for the relative attention allocated to each type of performance. This is a strong argument in favour of using DEA in the context of social enterprises. Social enterprises have a continuum of possibilities, with varying weights attributed to social and economic missions for which reliable information is often unavailable. Hence, DEA enables the social, economic and overall performance of social enterprises to be quantified and reported in a consistent and comparable manner while capturing their complexity. Furthermore, the resulting BoD weightings of DEA proxy the strategic orientation of social enterprises between social and economic objectives, as these weightings capture their relative priority (Cherchye et al. 2007b). They may therefore be a useful topology for social enterprises, since these organisations are confronted by a tension between social and economic objectives, and attending to them is a matter of relative priority (Stevens et al. 2015). ${ }^{5}$ In calculating these weightings over time, DEA provides a dynamic perspective on the strategic orientation of social enterprises toward social and economic objectives. Researchers should pay specific attention to weighting restrictions when using DEA for the 
performance measurement of social enterprises. ${ }^{6}$ Whereas weightings may vary between 0 and 100 per cent, there is a trade-off between mathematical optimisation and practical relevance. Indeed, previous research has pointed out the inherent difficulty that weightings can take unreasonable values (e.g. Cherchye et al. 2007a). Therefore, a proper weighting scheme requires the opinion of experts with a broad knowledge of the context to be incorporated. Using such insights generates weightings that are practically relevant but deal with the remaining uncertainty using the BoD method (Melyn and Moesen 1991).

In short, DEA provides two outputs for social enterprises which are highly relevant for researchers and institutions, namely (i) a performance measure for social, economic and overall efficiency, and (ii) weighting schemes as proxies for the strategic orientations of social enterprises. This novel methodology for measuring the performance of social enterprises allows for composite indicators (overall efficiency) and the weighting of single indicators (social and economic efficiency).

\section{Extending the Concept of Mission Drift in Social Enterprises}

Our application of DEA in the context of sheltered workshops highlights some interesting findings that contribute to the literature on mission drift in social enterprises. Our empirical analysis of the overall, economic and social performance of social enterprises suggests that they may face different types of mission drift.

Analysis of the bottom performers shows that they did not succeed in increasing their performance over time, even though they had the largest room for improvement (especially in their economic performance). This finding is peculiar, as one would expect bottom performers to increase their focus on economic objectives (Sullivan 2010). Indeed, Ketchen and Palmer (1999) argue that low economic performance creates a context in which organisations must first deal with their weak economic situation. The weighting allocation to the economic objectives of bottom performers was consistently lower over time than for top performers, suggesting that these social enterprises face the risk of mission lock-in (Copestake 2007). The phenomenon of mission lock-in can be explained by the threatrigidity theory, which suggests that low performance may result in increased rigidity rather than a change in the strategic orientation of the organisation (Staw et al. 1981). Weak performers systematically devote too much attention to their social mission, whereas they need to redirect their attention to their economic mission to achieve long-term sustainability ( Young et al., 2012).

Further analysis of the dynamics of performance and weighting allocations to social and economic objectives over time provides more detailed insights into how firms respond to specific environmental circumstances. We observe that social enterprises gradually increased their attention to social aspects during the financial crisis of 2007-2011. This suggests that social enterprises may have faced "reverse" 
mission drift during this period, as they increased their emphasis on their social missions. In the case of bottom performers, this reverse mission drift resulted in a decrease in economic efficiency, but this decrease was not compensated for by an increase in social efficiency. In the case of top performers, we find that they maintained high overall efficiency by compensating for deteriorating economic efficiency with stronger social efficiency. This behaviour of the top performers corresponds with the argument that social enterprises will divert attention toward their social mission once they have achieved high economic performance (Copestake 2007). High economic performance frees resources that can be allocated to strengthening social performance (Battilana et al. 2015), underpinning the view that transactional linkages may exist between social and economic objectives (Murphy and Coombes 2009). This also resonates with Bruneel et al.'s (2016) finding that social enterprises may face a hierarchy in balancing their social and economic goals. They must sequence their attention allocation between social and economic missions, giving priority to goals associated with long-term sustainability (i.e. economic).

However, our empirical analysis shows that the social enterprises responded differently during the period 2011-2013. Top-, mid- and bottom-quartile performers redirected their attention from the social to the economic, reflecting more a case of classic "mission drift". This period was characterised by a significant level of institutional uncertainty induced by new policy. The government would eventually adopt a new mechanism to determine the subsidies allocated to each sheltered workshop from 2015 onwards. This was part of a new policy that aimed to increase economic awareness in social enterprises and push them to become more business-like. In practice, this new policy measure implied that subsidies for sheltered workshops would decrease and that they would have to place greater reliance on income generated from commercial activities. Consequently, policy measures supporting the trend toward commercialisation and professionalisation of the social economy might be a potential cause of mission drift in social enterprises.

\section{Ethical Implications of our Study for Social Enterprises and Policy}

Taken together, the application of DEA as a novel methodology for measuring performance and the strategic orientation of social enterprises sheds new light on mission drift in social enterprises and leads to interesting ethical considerations. The literature cautions that social enterprises should beware of overemphasising commercial objectives, as this may negatively affect their realisation of social objectives. Social enterprises should therefore try to prevent mission drift in order to maintain a balance between social and economic goals (Ramus and Vaccaro 2014).

However, our empirical results show that placing stronger emphasis on economic objectives does not necessarily decrease social performance. On the contrary, the more economically-oriented social 
enterprises in our sample achieved superior economic and social performance compared with social enterprises that placed stronger emphasis on social objectives. In line with empirical work in the microfinance sector (see Mersland and Strøm 2010), this finding counters the fear that more economically-oriented social enterprises will drift away from their social missions. Social and economic value creation appear to be closely related, and achieving economic performance generates resources that can, in turn, be employed to strengthen social performance (Dacin et al. 2010, 2011). In other words, pursuing economic efficiency may be seen as an enabler of social mission (Wilson and Post 2013). In social entrepreneurship, there is a dominant view that social performance is in competition with economic performance and creates ethical challenges, such as a struggle to balance social and economic goals (Markman et al. 2016). Indeed, prioritising economic goals draws attention away from pro-social values (Ramus and Vaccaro 2014). Our results suggest that, from an ethical perspective, being economically-oriented as a social enterprise does not necessarily imply "bad behaviour", and being socially-oriented does not necessarily mean that the social enterprise is behaving morally.

In contrast, our analysis indicates that social enterprises with a stronger social orientation fail to achieve high social efficiency, compared with social enterprises that are more commercially oriented, while at the same time jeopardising firm sustainability due to their low economic efficiency. This resonates with previous research that has shown that overemphasis on a social mission may result in losing sight of commercial viability, ultimately contributing to organisational failure (Tracey et al. 2011). Our findings suggest that a stronger orientation toward the economic reflects "good" behaviour, as this results in higher economic and social performance, whereas the resistance of social enterprises to the general trend to become more business-like seems to reflect "bad" behaviour. This finding sheds new light on ethical issues in the context of social entrepreneurship. Traditionally, ethical issues relate to adhering to the organisation's economic mission at the expense of efforts to realise its social mission. Our study shows that lack of a commercial "attitude" may be more harmful to social enterprises than initially expected. Despite a stronger strategic orientation toward the social, bottom performers achieve lower overall, economic and social performance. Indeed, a lack of individualistic entrepreneurial drive results in a "frail entrepreneurial profile", which may equally underlie potential ethical issues (Bacq et al. 2014). Moreover, WISE companies receive subsidies to help them realise their social mission to employ workers from disadvantaged groups. The low social, economic and overall efficiency of more socially-oriented WISE companies indicates that the subsidies do not have a leveraging effect in realising their social mission.

Since performance measurement may play a role in policy decisions, the importance of accurate performance tools for governments cannot be underestimated. It is widely acknowledged that governments share a vision of a more effective social sector (Hart and Haughton 2007). As a 
consequence, governments are increasingly implementing institutional reforms that are drastically changing the environment in which social enterprises operate (Wellens and Jegers 2014). In particular, these waves of reforms are believed to be putting social enterprises under pressure to become business-like. Governments should therefore be conscious that they may have an indirect influence on the objectives set by social enterprises (Defourny and Nyssens 2008).

Using DEA to measure the social, economic and overall performance of social enterprises might provide guidance for governments on evaluating the impact of their policies. DEA allows governments to determine empirically whether individual social enterprises are operating efficiently. As a result, governments might develop more tailored support programmes for social enterprises at risk of reverse mission drift (i.e. top performers) and mission lock-in (i.e. bottom performers). Such tailored support programmes should benefit individual social enterprises and the social sector as a whole, since both social and economic efficiency in the sector will be pushed upwards. However, governments should also be aware of the effect of their policy measures on mission drift in social enterprises. Our results show that sheltered workshops, as a group, placed stronger emphasis on their economic objectives in response to institutional uncertainty generated by new policy pushing social enterprises to become more business-like (see Maatwerk Decree).

Furthermore, DEA allows governments to distinguish between efficient and inefficient social enterprises. Rather than subsidisation being driven by political objectives, which may result in allocation inefficiencies (Bergström 2000), our proposed performance measurement method may help governments to allocate their available resources as efficiently as possible. The efficiency scores provided by DEA will enable them to analyse which funds are making a difference, and whether it might be better to reallocate available funds to other social enterprises. Therefore, performance measurement using DEA might be used to publicly legitimise their allocation decisions (Ebrahim and Rangan 2014). Investors in social enterprises might also build on our methodology to guide their decision-making processes. ${ }^{7}$ Business angels and venture capitalists are investing increasingly in social enterprises, and the balance of social and economic objectives is key to their investment decisions. Specifically, investors will only back social enterprises if they can achieve sufficient economic sustainability to enable them to fulfil their ethical role in society (Scarlata and Alemany 2011). Employing DEA will allow investors in social enterprises to examine and monitor the performance and strategic orientation of potential investment opportunities as well as existing portfolio companies.

\section{Areas for Future Research}

Our study opens up several avenues for future research. First, DEA provides a significant opportunity for social entrepreneurship scholars to apply this straightforward technique in further empirical 
research on the performance of social enterprises. For example, in the strategic management field, it is often crucial to seek explanations of firms' efficiency (Chen et al. 2015). A two-stage approach offers a technique for performing such analyses. In the first stage, DEA models calculate the efficiency scores of firms in the sample. In the second stage, the efficiency scores obtained in the first stage are regressed on a collection of explanatory variables (e.g. Sun and Stuebs 2013; Basharat et al. 2015). Thus, DEA provides researchers with a methodology to approach the performance of social enterprises and to identify the determinants of social, economic and overall efficiency.

Our study is a first step in employing DEA analysis as a measurement methodology for the performance of social enterprises. Since the basic assumption implies that the organizations under study should belong to one frontier, the use of just one production frontier will lead to erroneous results if there is a mixture of production functions in the sample (i.e. heterogeneous groups in the sample). Nevertheless, the DEA methodology can also be applied for measuring the performance of firms across different groups (see, for example, O'Donell et al., 2008, who present a metafrontier framework). Furthermore, whereas our study starts from the overall performance of social enterprises, future studies might examine this in further detail by, for example, focusing primarily on social or economic performance. This might open new areas of more detailed research on the behaviour of social enterprises across different groups, for example by using social or economic performance as a point of departure.

Second, future research might employ the weightings of social and economic efficiency generated by the DEA methodology to analyse mission drift in social enterprises in greater detail. This would require the use of longitudinal datasets, as mission drift can be captured by shifts in the weightings of social and economic efficiency. Using the two-stage approach (Chen et al. 2015), these weightings can be used as dependent variables and regressed against potential sources of mission drift. For example, future studies might examine how firm-level factors, such as changes in the composition of the management team or board of directors, influence changes in the weightings. Similarly, researchers might study how changes in policy and support instruments for social enterprises affect their attention allocation along the social-economic continuum over time. In addition, the BoD weightings resulting from DEA may be a useful typology for social entrepreneurship activities. In essence, these weightings reflect the strategic orientation of the organisation toward social versus economic objectives. Consequently, the weightings allow social enterprises to be positioned on the social-economic continuum. Furthermore, although our results suggest that a stronger orientation towards the economic goals reflects "good" behaviour, it is also important to note that certain social enterprises 
might be facing poor performance "by construction"1. So adding more commercial orientation may not help there. Future research might explore the condition under which organisations can successfully change their orientation and subsequently enhance performance.

Finally, while our study uses DEA in the context of WISE, this methodology might be applied to other types of organisation pursuing multiple goals. For example, future research might use the DEA methodology to analyse the performance of companies with the goal of environmental performance or providing microfinancing (e.g. Martínez-Campillo et al. 2016). Existing research on mission drift analyses this primarily in the context of social enterprises, such as abandoning a social mission in favour of an economic mission (Battilana et al. 2012; Mair et al. 2015). However, companies in the regular economy are also increasingly being pushed to take account of non-economic objectives and address social and environmental goals (Wellens and Jegers 2014; Eikenberry and Kluver 2004). Whereas existing research focuses mainly on the economic performance of regular companies, future research might use the DEA methodology to study the extent to which they successfully realise such noneconomic objectives. As society is imposing non-economic objectives, regular companies are also becoming more hybrid in nature as they shift away from a pure for-profit orientation. As a result, regular companies must increasingly pay attention to issues relating to social and environmental sustainability. This, in turn, may put pressure on their commitment to accomplishing their dominant economic mission. Future studies might therefore apply the DEA methodology, and more specifically the weighting allocation between economic and non-economic objectives, to examine potential mission drift in regular companies.

\section{Conclusion}

This study enhances our understanding of performance measurement and challenges the generally accepted view of mission drift in social enterprises. Specifically, empirical analysis of the overall, economic and social performance of top- and bottom-performing social enterprises suggests that social enterprises may face different types of mission drift. On the one hand, top performers are confronted with "reverse" mission drift: they will pay attention to the social once they have achieved high economic performance. On the other hand, bottom performers are confronted with mission "lock-in": they systematically allocate too much attention to the social. This study therefore underpins the view that transactional linkages may exist between social and economic objectives, and that social enterprises may need to sequence their attention allocation between the social and the economic in order to prioritise goals associated with firm sustainability.

\footnotetext{
${ }^{1}$ We thank an anonymous reviewer for raising this point
} 
Tables and Figures

Table 1: Descriptions of variables (before normalisation)

\begin{tabular}{lrrrrr}
\hline \hline \multicolumn{2}{c}{ Outputs } & \multicolumn{2}{c}{ Inputs } \\
\hline \hline & Return & $\begin{array}{r}\text { FTE target } \\
\text { employees }\end{array}$ & $\begin{array}{r}\text { Tangible fixed } \\
\text { assets }\end{array}$ & Contingent & $\begin{array}{r}\text { Operating } \\
\text { costs }\end{array}$ \\
\hline Mean & $5,331,246$ & 259.18 & $4,582,147$ & 254.35 & $10,222,110$ \\
\hline Std. Dev. & $7,006,569$ & 262.56 & $4,625,650$ & 244.05 & $11,522,670$ \\
\hline 25th percentile & $1,617,109$ & 111.65 & $1,354,660$ & 113.00 & $3,784,477$ \\
\hline Median & $3,175,306$ & 197.71 & $3,278,177$ & 189.00 & $6,768,372$ \\
\hline 75th percentile & $6,579,774$ & 288.78 & $6,152,530$ & 294.50 & $12,075,730$ \\
\hline Min & 163,313 & 26.80 & 95,192 & 29.00 & 768,729 \\
\hline Max & $52,331,418$ & $1,515.00$ & $26,769,600$ & $1,348.00$ & $82,250,970$ \\
\hline \hline No. of observations & 542 & 542 & 542 & 542 & 542 \\
\hline \hline
\end{tabular}

Table 2: Efficiency scores

\begin{tabular}{lrrr}
\hline \hline & \multicolumn{3}{c}{ Estimated models: } \\
\hline \hline Mean & $\begin{array}{r}\text { Overall } \\
\text { efficiency }\end{array}$ & $\begin{array}{r}\text { Social } \\
\text { efficiency }\end{array}$ & $\begin{array}{r}\text { Economic } \\
\text { efficiency }\end{array}$ \\
\hline Std. Dev. & 0.9152 & 0.8578 & 0.6790 \\
\hline 25th percentile & 0.0646 & 0.0814 & 0.1698 \\
\hline Median & 0.8682 & 0.7987 & 0.5670 \\
\hline 75th percentile & 0.9199 & 0.8545 & 0.6649 \\
\hline Min & 0.9729 & 0.9168 & 0.7942 \\
\hline Max & 0.6952 & 0.5835 & 0.2213 \\
\hline Fully efficient DMU & 1 & 1 & 1 \\
\hline \hline No. of observations & 98 & 47 & 32 \\
\hline \hline
\end{tabular}

Table 3: Top-, mid- and bottom-quartile performers

\begin{tabular}{llll}
\hline \hline \multicolumn{3}{c}{ Descriptive statistics } \\
\hline \hline Return & Top performer & Mid performer & Bottom performer \\
\hline FTE target employees & $6,934,840$ & $5,830,15$ & $2,913,11$ \\
\hline Tangible fixed assets & $3,956,11$ & 297.22 & 180.62 \\
\hline Contingent & 243.44 & $5,416,067$ & $3,468,79$ \\
\hline Operating costs & $11,592,894$ & $11,368,199$ & 194.12 \\
\hline Overall efficiency & 0.9829 & 0.9180 & $0.845,81$ \\
\hline Social efficiency & 0.9137 & 0.8569 & 0.8074 \\
\hline Economic efficiency & 0.7897 & 0.6856 & 0.5598 \\
\hline
\end{tabular}




\section{Figure 1: Efficiency scores}
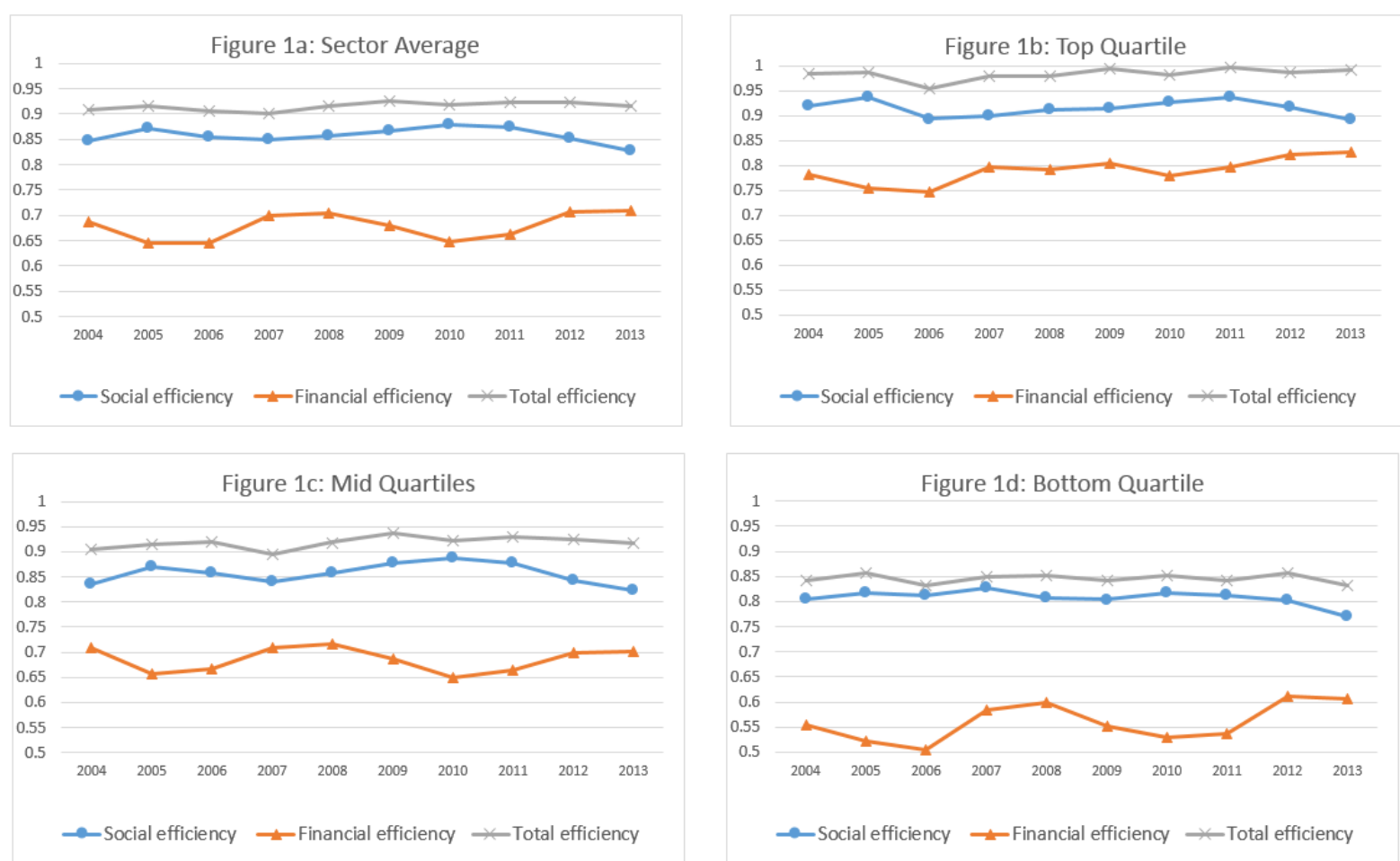

Figure 2: Economic orientation

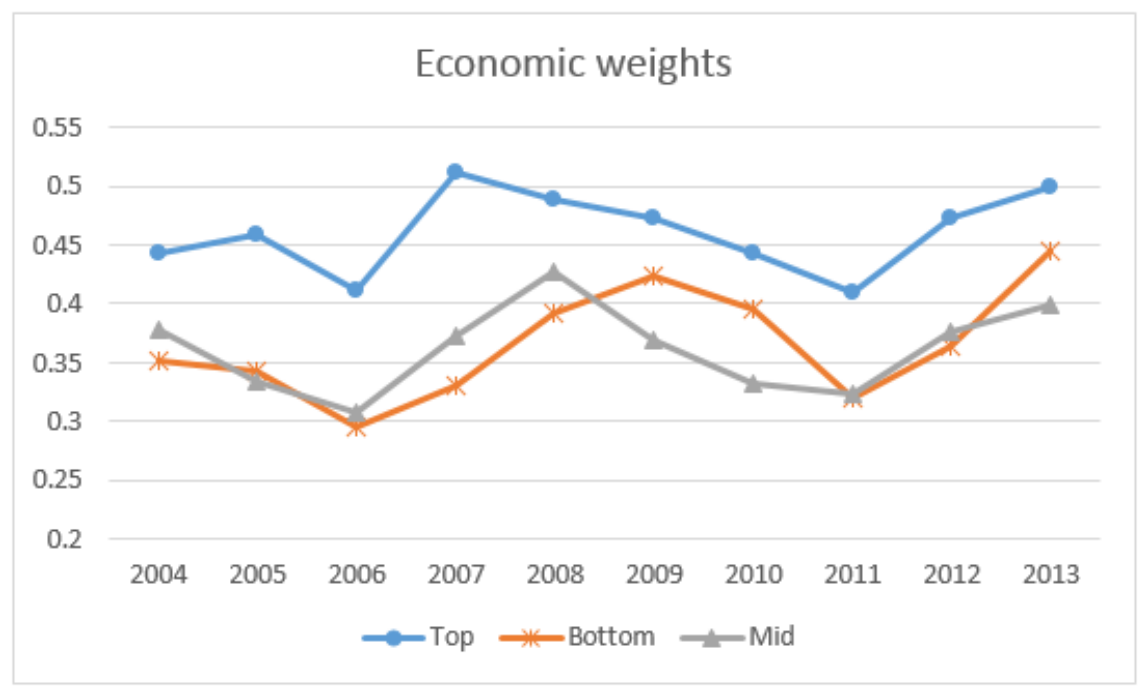




\section{Appendix}

Table A: Correlation matrix of overall efficiency with different weighting restrictions

\begin{tabular}{llll}
\hline \hline Weighting scheme & \multicolumn{1}{c}{$\mathrm{P}=\mathbf{0 . 8}$} & $\mathrm{P}=\mathbf{0}$ & $\mathrm{P}=\mathbf{0 . 5}$ \\
\hline $\mathrm{P}=\mathbf{0 . 8}$ & 1.0000 & & \\
\hline $\mathrm{P}=\mathbf{0}$ & $0.9825^{* *}$ & 1.0000 & \\
\hline $\mathrm{P}=\mathbf{0 . 5}$ & $0.8975^{* *}$ & $0.8230^{* *}$ & 1.0000 \\
\hline
\end{tabular}

Note: ${ }^{* *} p<0.01$

\section{Compliance with Ethical Standards}

1. Conflicts of Interest

The authors declare that they have no conflicts of interest.

2. Research involving human participants and/or animals

This work does not contain any studies with human participants or animals performed by any of the authors.

3. Informed consent

Informed consent was obtained from all individual participants in the study. 


\section{References}

André, K., \& Pache, A. C. (2016). From caring entrepreneur to caring enterprise: Addressing the ethical challenges of scaling up social enterprises. Journal of Business Ethics, 133(4), 659-675.

Bacq, S., Hartog, C., \& Hoogendoorn, B. (2014). Beyond the moral portrayal of social entrepreneurs: An empirical approach to who they are and what drives them. Journal of Business Ethics, 133(4), 703-718.

Banker, R. D., Charnes, A., \& Cooper, W. W. (1984). Some models for estimating technical and scale inefficiencies in data envelopment analysis. Management Science, 30, 1078-1092

Banker, R. D., \& Natarajan, R. (2008). Evaluating contextual variables affecting productivity using data envelopment analysis. Operations Research, 56(1), 48-58.

Bartkus, B. R., \& Glassman, M. (2008). Do firms practice what they preach? The relationship between mission statements and stakeholder management. Journal of Business Ethics, 83(2), 207-216.

Basharat, B., Hudon, M., \& Nawaz, A. (2015). Does efficiency lead to lower prices? A new perspective from microfinance interest rates. Strategic Change, 24(1), 49-66.

Battilana, J., \& Lee, M. (2014). Advancing research on hybrid organizing: Insights from the study of social enterprises. The Academy of Management Annals, 8(1), 397-441.

Battilana, J., Lee, M., Walker, J., \& Dorsey, C. (2012). In search of the hybrid ideal. Stanford Social Innovation Review, 10(3), 51-55.

Battilana, J., Sengul, M., Pache, A. C., \& Model, J. (2015). Harnessing productive tensions in hybrid organizations: The case of work integration social enterprises. Academy of Management Journal, 58(6), 1658-1685.

Bellucci, M., Bagnoli, L., Biggeri, M., \& Rinaldi, V. (2012). Performance measurement in solidarity economy organization: The case of Fair Trade shops in Italy. Annals of Public \& Cooperative Economics, 83(1), 25-59.

Belu, C. (2009). Ranking corporations based on sustainable and socially responsible practices: A data envelopment analysis (DEA) approach. Sustainable Development, 17(4), 257-268. 
Bergström, F. (2000). Capital subsidies and the performance of firms. Small Business Economics, 14(3), 83-93.

Bharty, N., \& Chitnis, A. (2015). Size and efficiency of MFIs: A data envelopment analysis of Indian MFIs. Enterprise Development \& Microfinance, 27(4): 255-272.

Boschee, J. (1995). Social entrepreneurship. Across the Board, 32(3), 20-25.

Bruneel, J., Moray, N., Stevens, R., \& Fassin, Y. (2016). Balancing competing logics in for-profit social enterprises: A need for hybrid governance. Journal of Social Entrepreneurship, 676(April), 1-26.

Bull, M. (2007). "Balance”: The development of a social enterprise business performance analysis tool. Social Enterprise Journal, 3(1), 49-66.

Certo, S. T., \& Miller, T. (2008). Social entrepreneurship: Key issues and concepts. Business Horizons, 51(4), 267-271.

Charnes, A., Cooper, W. W., \& Rhodes, E. L. (1978). Measuring the efficiency of decision making units. European Journal of Operational Research, 2, 429-444.

Chen, C., \& Delmas, M. (2011). Measuring corporate social performance: An efficiency perspective. Production and Operations Management, 20(6), 789-804.

Chen, C., Delmas, M. A., \& Lieberman, M. B. (2015). Production frontier methodologies and efficiency as a performance measure in strategic management research. Strategic Management Journal, $36,315-334$.

Cherchye, L. (2001). Using data envelopment analysis to assess macroeconomic policy performance. Applied Economics, 33(3), 407-416.

Cherchye, L., De Rock, B., Dierynck, B., Roodhooft, F., \& Sabbe, J. (2013). Opening the "black box" of efficiency measurement: Input allocation in multioutput settings. Operations Research, 61(5), $1148-1165$.

Cherchye, L., De Rock, B., \& Hennebel, V. (2014). The economic meaning of data envelopment analysis: A behavioral perspective. Socio-Economic Planning Sciences, 48(1), 29-37.

Cherchye, L., Lovell, C. A. K., Moesen, W., \& Van Puyenbroeck, T. (2007a). One market, one number? 
A composite indicator assessment of EU internal market dynamics. European Economic Review, $51,749-779$.

Cherchye, L., \& Kuosmanen, T. (2006). Benchmarking sustainable development: A synthetic meta-index approach. In M. McGillivray \& M. Clarke (Eds.), Perspectives on human development (Ch. 7). Tokyo: United Nations University Press.

Cherchye, L., Moesen, W., Rogge, N., \& Van Puyenbroeck, T. (2007b). An introduction to "benefit of the doubt" composite indicators. Social Indicators Research, 82(1), 111-145.

Copestake, J. (2007). Mainstreaming microfinance: Social performance management or mission drift? World Development, 35(10), 1721-1738.

Crucke, S., \& Knockaert, M. (2016). When stakeholder representation leads to faultlines: A study of board service performance in social enterprises. Journal of Management Studies, 53(5), 768-793.

Crucke, S., \& Decramer, A. (2016). The development of a measurement instrument for the organizational performance of social enterprises. Sustainability, 8(2), 161.

Dacin, M. T., Dacin, P. A., \& Tracey, P. (2011). Social entrepreneurship: A critique and future directions. Organization Science, 22(5), 1203-1213.

Dacin, P. A., Dacin, M. T., \& Matear, M. (2010). Social entrepreneurship: Why we don't need a new theory and how we move forward from here. Academy of Management Perspectives, 24, 37-58.

De Clercq, D., \& Voronov, M. (2011). Sustainability in entrepreneurship: A tale of two logics. International Small Business Journal, 29(4), 322-344.

Dees, J. G. (1998). The meaning of social entrepreneurship. Innovation, 2006(11-4-06), 1-6.

Dees, G. J. (2001). Mobilizing resources. In G. J. Dees, J. Emerson, \& P. Economy (Eds.), Enterprising nonprofits (pp. 63-102). New York: John Wiley \& Sons

Defourny, J., \& Nyssens, M. (2008). Social enterprise in Europe: Recent trends and developments. Social Enterprise Journal, 4(3), 202-228.

Doherty, B., Haugh, H., \& Lyon, F. (2014). Social enterprises as hybrid organizations: A review and research agenda. International Journal of Management Reviews, 16(4), 417-436. 
Ebrahim, A., Battilana, J., \& Mair, J. (2014). The governance of social enterprises: Mission drift and accountability challenges in hybrid organizations. Research in Organizational Behavior, 34, 81100.

Ebrahim, A., \& Rangan, V. K. (2010). Putting the brakes on impact: A contingency framework for measuring social performance. Academy of Management Proceedings, Meeting Abstract Supplement, 1-6.

Ebrahim, A., \& Rangan, V. K. (2014). What impact? A framework for measuring the scale and scope of social performance. California Management Review, 56(3), 118-141.

Eikenberry, A. M., \& Kluver, J. D. (2004). The marketization of the nonprofit sector: Civil society at risk? Public Administration Review, 64(2), 132-140.

Flockhart, A. (2005). The use of social return on investment (SROI) and investment ready tools (IRT) to bridge the financial credibility gap. Social Enterprise Journal, 1(1), 29-42.

Gelb, D., \& Strawser, J. A. (2001). Corporate social responsibility and financial disclosures: An alternative explanation for increased disclosure. Journal of Business Ethics, 33(1), 1-13.

Golany, B. \& Roll, Y. (1989). An application procedure for DEA. Omega, 17(3), 237-250.

Gonin, M., Besharov, M., Smith, W., \& Gachet, N. (2012). Managing social-business tensions : A review and research agenda for social enterprise. Academy of Management Proceedings, Meeting Abstract Supplement, 11745.

Gulland, A. (2011). Social enterprises need to prove value for money, says public spending watchdog. $B M J, 342, \mathrm{~d} 4077$.

Gutierrez-Nieto, B., Serrano-Cinca, C., \& Molinero, C. M. (2007). Microfinance institutions and efficiency. OMEGA - The International Journal of Management Science, 35, 131-142.

Gutiérrez-Nieto, B., Serrano-Cinca, C., \& Mar Molinero, C. (2009). Social efficiency in microfinance institutions. Journal of the Operational Research Society, 60(1), 104-119.

Halkos, G. E., \& Tzeremes, N. G. (2010). The effect of foreign ownership on SMEs performance: An efficiency analysis perspective. Journal of Productivity Analysis, 34(2), 167-180. 
Harrison, J., \& Rouse, P. (2016). DEA and accounting performance measurement. In S.-N. Hwang, H.-S. Lee, \& J. Zhu (Eds.), Handbook of operations analytics using data envelopment analysis (pp. 385412). New York, NY: Springer.

Hart, T., \& Haughton, G. (2007). Assessing the economic and social impacts of social enterprise. Research paper, Centre for City and Regional Studies, University of Hull. Available at: https://www.escholar.manchester.ac.uk/ (accessed 15 June 2012).

Kaplan, R. (2001). Strategic performance measurement and management in nonprofit organizations. Nonprofit Management \& Leadership, 3(Spring), 353-370.

Ketchen, D., \& Palmer, T. (1999). Strategic responses to poor organization performance: A test of competing perspectives. Journal of Management, 25, 683-706.

Kroeger, A., \& Weber, C. (2014). Developing a conceptual framework for comparing social value creation. Academy of Management Review, 39(4), 513-540.

Kuosmanen, T., \& Kortelainen, M. (2005). Measuring eco-efficiency of production with data envelopment analysis. Journal of Industrial Ecology, 9(4), 59-72.

La Porta, R., Lopez-De-Silanes, F., Schleifer, A., \& Vishny, R. W. (1997). Legal determinants of external finance. The Journal of Finance, 52(3), 1131-1150.

Lu, W.-M., Wang, W.-K., \& Lee, H. L. (2013). The relationship between corporate social responsibility and corporate performance: Evidence from the US semiconductor industry. International Journal of Cleaner Production Research, 51(19), 5683-5695.

Maas, K., \& Liket, K. (2011). Social impact measurement: Classification of methods. In R. Burritt, S. Schaltegger, M. Bennett, T. Pohjola, \& M. Csutora (Eds.), Environmental management accounting and supply chain management (pp. 171-202). Delft, Netherlands: Springer.

Mair, J., Mayer, J., \& Lutz, E. (2015). Navigating institutional plurality: Organizational governance in hybrid organizations. Organization Studies, 36, 713-739.

Markman, G. D., Russo, M., Lumpkin, G. T., Jennings, P. D., \& Mair, J. (2016). Entrepreneurship as a platform for pursuing multiple goals: A special issue on sustainability, ethics, and 
entrepreneurship. Journal of Management Studies, 53(5), 673-694.

Martínez-Campillo, A., Fernández-Santos, Y., \& Del Pilar Sierra-Fernández, M. (2016). How well have social economy financial institutions performed during the crisis period? Exploring financial and social efficiency in Spanish credit unions. Journal of Business Ethics, doi: 10.1007/s10551-0163192-9.

Melyn, W., \& Moesen, W. (1991). Towards a synthetic indicator of macroeconomic performance: Unequal weighting when limited information is available. Public Economic Research Paper 17, CES, KU Leuven, Belgium.

Mersland, R., \& Strøm, R. Ø. (2010). Microfinance mission drift? World Development, 38(1), 28-36.

Millar, R., \& Hall, K. (2012). Social return on investment (SROI) and performance measurement: The opportunities and barriers for social enterprises in health and social care. Public Management Review, 15(6), 923-941.

Murphy, P. J., \& Coombes, S. M. (2009). A model of social entrepreneurial discovery. Journal of Business Ethics, 87(3), 325-336.

Nicholls, A. (2009). "We do good things, don't we?": "Blended value accounting" in social entrepreneurship. Accounting, Organizations and Society, 34(6-7), 755-769.

O'Donnell, C., Rao, D., Battese, G., 2007. Metafrontier frameworks for the study of firm-level efficiencies and technology ratios. Empirical Economics 34, 231-255

Ramus, T., \& Vaccaro, A. (2014). Stakeholders matter: How social enterprises address mission drift. Journal of Business Ethics, 143(2), 307-322.

Rodríguez-Pérez, G., Slof, J., Solà, M., Torrent, M., \& Vilardell, I. (2011). Assessing the impact of fairvalue accounting on financial statement analysis: A data envelopment analysis approach. Abacus, 47(1), 61-84.

Rotheroe, N., \& Richards, A. (2007). Social return on investment and social enterprise: Transparent accountability for sustainable development. Social Enterprise Journal, 3(1), 31-48.

Sarkis J. (2007). Preparing your data for DEA. In J. Zhu, \& W. D. Cook (Eds.), Modeling data irregularities 
and structural complexities in data envelopment analysis (pp. 305-320). New York, NY: Springer Science Business Media.

Scarlata, M., \& Alemany, L. (2011). Deal structuring in philanthropic venture capital investments: Financing instrument, valuation and covenants. Journal of Business Ethics, 95, 121-145.

Smith, W. K., Gonin, M., \& Besharov, M. L. (2013). Managing social-business tensions. Business Ethics Quarterly, 23(3), 407-442.

Stevens, R., Moray, N., \& Bruneel, J. (2015a). The social and economic mission of social enterprises: Dimensions, measurement, validation, and relation. Entrepreneurship: Theory and Practice, 39(5), 1051-1082.

Stevens, R., Moray, N., Bruneel, J., \& Clarysse, B. (2015b). Attention allocation to multiple goals: The case of for-profit social enterprises. Academy of Management Journal, 36, 1006-1016.

Staw, B. M., Sandelands, L. E., \& Dutton, J. E. (1981). Threat-rigidity effects in organizational behavior: A multi-level analysis. Administrative Science Quarterly, 26, 501-524.

Sullivan, B. N. (2010). Competition and beyond: Problems and attention allocation in the organizational rulemaking process. Organization Science, 21(2), 432-450.

Sun, L., \& Stuebs, M. (2013). Corporate social responsibility and firm productivity: Evidence from the chemical industry in the United States. Journal of Business Ethics, 118(2), 251-263.

Tracey, P., Phillips, N., \& Jarvis, O. (2011). Bridging institutional entrepreneurship and the creation of new organizational forms: A multilevel model. Organization Science, 22, 60-80.

Wellens, L., \& Jegers, M. (2014). Effective governance in nonprofit organizations: A literature based multiple stakeholder approach. European Management Journal, 32(2), 223-243.

Wilson, F., \& Post, J. E. (2013). Business models for people, planet (\& profits): Exploring the phenomena of social business, a market-based approach to social value creation. Small Business Economics, $40,715-737$.

Young, D. R., Kerlin, J. A., Teasdale, S., \& Soh, J. (2012). The dynamics and long-term stability of social enterprise. In J. Kickul, \& S. Bacq (Eds.), Patterns in social entrepreneurship research (pp. 217- 
242). Cheltenham: Edward Elgar.

Zahra, S. A., Gedajlovic, E., Neubaum, D. O., \& Shulman, J. M. (2009). A typology of social entrepreneurs: Motives, search processes and ethical challenges. Journal of Business Venturing, 24(5), 519-532.

Zaim, O., Färe, R., \& Grosskopf, S. (2001). An economic approach to achievement and improvement indexes. Social Indicators Research, 56, 91-118.

\section{Notes}

1 To obtain balanced panel data, we limited our study to 2004 and, where possible, missing data were collected by contacting the firms or examining online annual accounts (available at: https://www.nbb.be/nl). It proved impossible to fill in the missing values for one particular firm. As a consequence, eight observations (for the same firm) were lost. Excluding this firm from our analysis did not influence the efficiency scores, so we decided to keep it in the dataset. In summary, we had 542 observations of 55 firms over a period of 10 years, with eight missing values for one organisation.

2 In order to get good discriminatory power out of DEA models, several scholars have established rules of thumb for the number of inputs and outputs to select and their relation to the number of decision-making units (DMU) (Sarkis 2007). The most strict rule is a total number of DMU of twice the product of the number of input and output variables. Our model with two inputs, two outputs and $55 \mathrm{DMU}$ satisfies this rule. Imbalances in the magnitude of inputs and outputs may also cause issues in DEA models. One of the best ways to avoid such issues is to have inputs and outputs of the same or similar magnitude (Sarkis 2007). Therefore, we mean-normalized all variables, as commonly applied in the DEA literature (see Cherchye et al. 2007a).

3 This approach is followed by papers in top journals to sort firms into quartiles by their aggregate performance and compare the top, mid and bottom quartiles (e.g., La Porta et al. 1997; Gelb and Strawser 2001). For instance, this approach has also been used by La Porta et al. (1997) to compare 49 countries, and by Harrison and Rouse (2016) to compare DEA efficiency scores.

4 According to the Kolmogorov-Smirnoff test, differences in the distribution of top, mid and bottom quartiles were significant at a $\mathrm{p}$ value $<0.01$.

5 We thank an anonymous reviewer for pointing this out to us.

6 We thank an anonymous reviewer for pushing our thinking on this point.

7 We thank an anonymous reviewer for pointing this out to us. 